\title{
Photochemical Unmasking of Polyyne Rotaxanes
}

\author{
Steffen L. Woltering, Przemyslaw Gawel, Kirsten E. Christensen, Amber L. Thompson, \\ and Harry L. Anderson*
}

Department of Chemistry, Chemistry Research Laboratory, University of Oxford, Oxford OX1 3TA, UK.

\begin{abstract}
Bulky photo-labile masked alkyne equivalents (MAEs) are needed for the synthesis of polyyne polyrotaxanes, as insulated molecular wires and as stabilized forms of the linear polymeric allotrope of carbon, carbyne. We have synthesized a novel MAE based on phenanthrene and compared it with an indane-based MAE. Photochemical unmasking of model compounds was studied at different wavelengths $(250 \mathrm{~nm}$ and $350 \mathrm{~nm})$, and key products were identified by NMR spectroscopy and X-ray crystallography. UV irradiation at $250 \mathrm{~nm}$ leads to unmasking of both MAEs. Irradiation of the phenanthrene system at $350 \mathrm{~nm}$ results in quantitative dimerization via [2+2] cycloaddition to form a [3]-ladderane; irradiation of this ladderane at $250 \mathrm{~nm}$ generates a dihydrotriphenylene, which can be oxidized easily to a triphenylene. Irradiation of the indane-based MAE at $350 \mathrm{~nm}$ in the presence of traces of oxygen forms an endoperoxide and a bisepoxide. Both MAEs have been incorporated into rotaxanes via copper-mediated active metal template Glaser or Cadiot-Chodkiewicz coupling. The identity of the rotaxanes was confirmed by NMR spectroscopy and mass spectrometry. The phenanthrene rotaxane decomposes during attempted photochemical unmasking, whereas photolysis of the indane rotaxane results in unmasking of the polyyne thread to form a rotaxane with a chain of $16 s p$-hybridized carbon atoms. This approach opens avenues towards the synthesis of encapsulated carbon allotropes.
\end{abstract}

\section{INTRODUCTION}

The predicted electronic and mechanical properties of carbyne, the linear $s p$-hybridized allotrope of carbon, ${ }^{1,2}$ have been debated for many years, ${ }^{3,4}$ providing a motivation for synthesizing this elusive carbon polymer. However, if carbyne could be prepared as an undiluted carbon allotrope, it is expected to be unstable and explosive, because acetylenic chains easily react with each other to form cross-linked materials, ${ }^{5-7}$ in a process that is highly exothermic. ${ }^{8}$ End-capped oligomeric analogues of carbyne, known as polyynes, have been prepared with chains of up to $44 s p$-hybridized carbon atoms, stabilized by bulky terminal groups. ${ }^{9,10}$ This strategy is unlikely to be effective for stabilizing longer polyynes, because the influence of the end-groups diminishes as the chain gets longer. Polyynes have previously been stabilized by rotaxane formation, ${ }^{11,12}$ helical wrapping ${ }^{13}$ and co-crystallization with metal complexes. ${ }^{14}$ Very long polyynes, consisting of more than 6,000 carbon atoms, have been created and studied inside carbon nanotubes. ${ }^{15}$ However, this type of encapsulation largely screens the properties of the guest; for example, it is difficult to measure the charge transport, optical or mechanical properties of a polyyne inside a carbon nanotube, because all these aspects are dominated by the host nanotube. The most versatile strategy for creating stable forms of carbyne is probably to synthesize polyrotaxanes in which the carbon chain is threaded through many macrocycles to form an insulated molecular wire'. ${ }^{16}$ Threading also offers a strategy to stabilize the cyclic analogues of carbyne, cyclo[ $n]$ carbons, ${ }^{1}$ by catenane formation, which would not be possible using encapsulation inside carbon nanotubes. Here we present an approach to the synthesis of polyyne rotaxanes using photo-labile masking groups. This chemistry opens an avenue towards carbyne polyrotaxanes and cyclocarbon catenanes.

Polyyne rotaxanes have been prepared previously using active metal templates. ${ }^{12,17-20}$ This strategy enables a single mac- rocycle to be threaded round a polyyne, but it does not provide access to polyyne polyrotaxanes with many threaded macrocycles, unless temporary alkyne-masking groups can be used to prevent unthreading. Various masked alkyne equivalents (MAEs) have been developed, particularly for the synthesis of cyclo $[n]$ carbons. MAEs are molecular subunits that can be transformed into alkynes by activation with light, ${ }^{21-23}$ heat $^{24,25}$ or chemical reagents ${ }^{26-28}$ (Scheme 1). Here, we explore the use of MAEs in the synthesis of polyyne rotaxanes. Our choice of MAEs is governed by the following factors: (i) the MAE must be chemically stable under the conditions of rotaxane formation; (ii) it should be bulky enough to act as a temporary stopper and prevent unthreading of the rotaxane; (iii) unmasking of the MAE must be possible in interlocked systems, and (iv) the MAE should be easy to synthesize. Photo-labile MAEs are appealing because they are expected to be stable under the conditions of rotaxane formation. Here, we investigate a new photo-labile MAE, based on the susceptibility of phenanthrene to undergo reversible photochemical $[2+2]$-cycloadditions to the double bond of the central ring (9,10-position). We compare this new MAE with an indane-based MAE developed by Tobe and coworkers. ${ }^{21}$ The photochemistry of both MAEs was investigated and some unexpected products were identified. Polyyne rotaxanes containing both types of MAEs were synthesized, but only the rotaxane with indane-based MAEs underwent clean photochemical unmasking. 
Scheme 1. Examples of Masked Alkyne Equivalents.

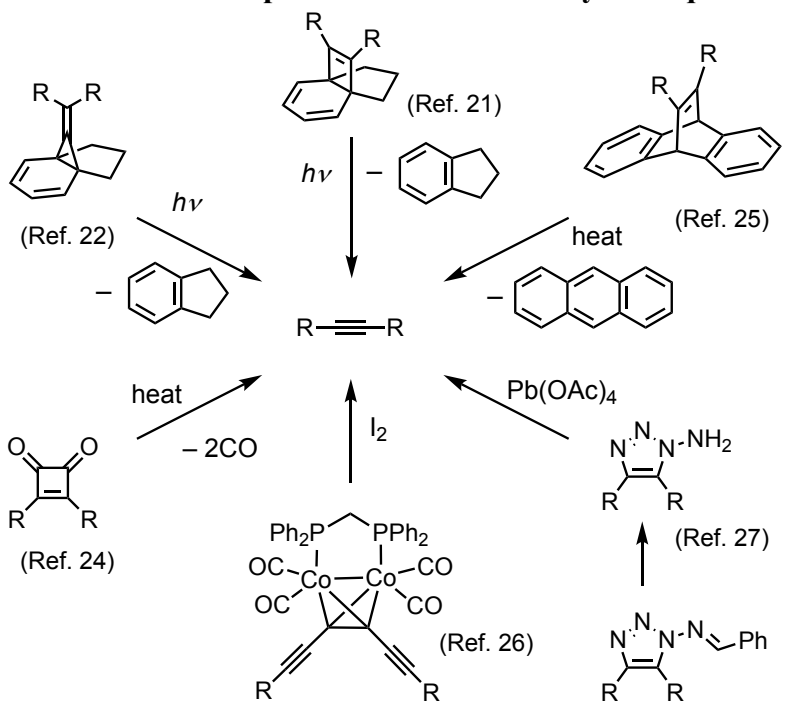

\section{RESULTS \& DISCUSSION}

\section{Synthesis and testing of MAEs}

The dichlorocyclobutene $\mathbf{1}$ is readily prepared from phenanthroline by photochemical addition of trichloroethylene followed by elimination of hydrogen chloride, as reported by Hacker and McOmie (Figure 1). ${ }^{29}$ Sonogashira coupling was used to prepare the TIPS-protected model compound $\mathbf{2}$. The crystal structure of $\mathbf{2}$ confirms the structure and gives an indication of its steric bulk (Figure 1c). ${ }^{30}$ We compared this phenanthrene-based MAE with an indane-based MAE developed by Tobe and coworkers. ${ }^{21} \mathrm{~A}$ drawback of the indane group is its longer synthesis: indane dichloride $\mathbf{3}$ is prepared in eight steps from cyclopentanone (Figure 1b). ${ }^{21 \mathrm{~d}}$ The TIPS-protected model compound $\mathbf{4}$ was prepared for comparison with $\mathbf{2}$.

Irradiation of compound 2 as a solution in $\mathrm{CDCl}_{3}(0.2 \mathrm{M}$ concentration) with UV light (wavelength $250 \mathrm{~nm}$ ) for $21 \mathrm{~h}$ leads to formation of phenanthrene in $80 \%$ yield, as illustrated by the ${ }^{1} \mathrm{H}$ NMR spectra in Figure 2. TIPS-triyne $\mathbf{5}$ is also formed in this reaction (Figure 3$)$, although in poor yield $(20 \%$ by NMR analysis) together with a complex mixture of products. A reference experiment showed that TIPS-triyne $\mathbf{5}$ is stable under the conditions of this photolysis, implying that the side products come from competing side reactions of $\mathbf{2}$, rather than from decomposition of triyne $\mathbf{5}$.

We also tested irradiation of $\mathbf{2}$ with UV light at longer wavelengths. Surprisingly, irradiation at $350 \mathrm{~nm}$ gave no phenanthrene; instead the [2+2] dimer, [3]-ladderane $\mathbf{6}$, is formed quantitatively as a single diastereomer (as seen from the ${ }^{1} \mathrm{H}$ NMR spectra in Figure 4 and X-ray crystal structure in Figure $3 \mathrm{~b}){ }^{30}$ The geometry of $\mathbf{6}$ is similar to those of previously reported ladderanes, ${ }^{31}$ but steric congestion results in an unusually long bond length for the $\mathrm{C}-\mathrm{C}$ bonds shared between two cyclobutane units (bond length 1.604(2) A; see Supporting Information, Section S6 for a comparison of bond lengths from CSD and Section S7 for computational studies).
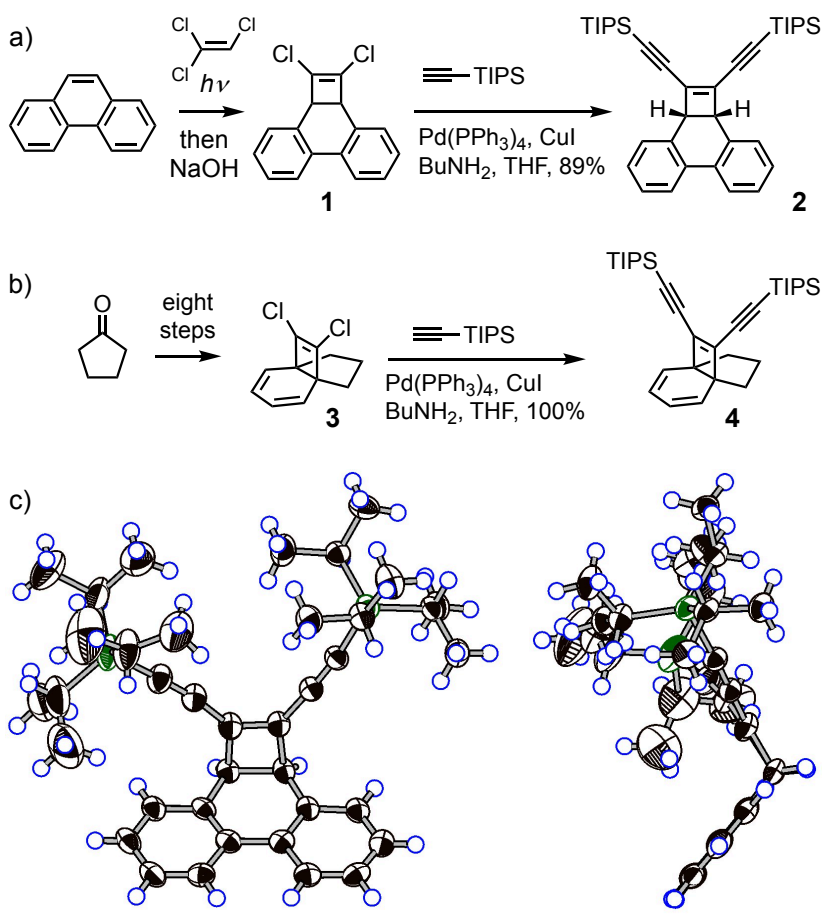

Figure 1. (a,b) Synthesis of MAEs models 2 and 4; (c) two orthogonal views of the structure of compound $\mathbf{2}$ in the crystal (thermal ellipsoids plotted at the $40 \%$ level).

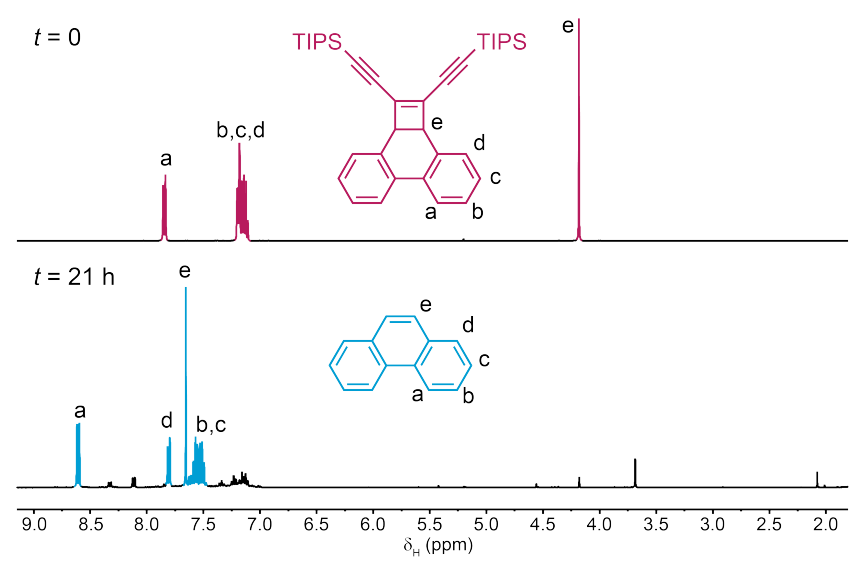

Figure 2. ${ }^{1} \mathrm{H}$ NMR spectra $\left(\mathrm{CDCl}_{3}, 298 \mathrm{~K}, 400 \mathrm{MHz}\right)$ of a solution of 2 (red peaks) before and after irradiation with UV light ( $250 \mathrm{~nm}$, no purification). Phenanthrene (blue peaks) is the major product $(80 \%)$ after irradiation for $21 \mathrm{~h}$. Triyne $\mathbf{5}$ could be detected by ${ }^{1} \mathrm{H}$ and ${ }^{13} \mathrm{C}$ NMR (yield $20 \%$ by ${ }^{1} \mathrm{H}$ NMR).

The unexpected outcome of the irradiation of 2 at $350 \mathrm{~nm}$ led to us to question whether [3]-ladderane 6 might be an intermediate in the cycloreversion observed on irradiation of 2 at $250 \mathrm{~nm}$. This can be ruled out as dimer 6 does not yield the unmasked triyne $\mathbf{5}$ when irradiated with $250 \mathrm{~nm}$ UV light; instead it generates a different product 7 (50\% yield) with only one phenanthrene unit expelled (Figure 3a). The formation of different products on irradiation at 250 and $350 \mathrm{~nm}$ must reflect the reactivity of different excited states. Compound 7 is also formed as a minor product $(\sim 10 \%)$ when 2 is irradiated with $250 \mathrm{~nm}$ UV light (peak at $3.77 \mathrm{ppm}$ in Figure 2). 
a)

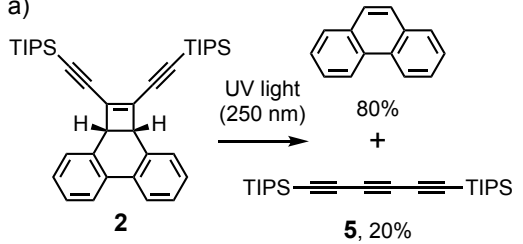

UV light $\downarrow(350 \mathrm{~nm})$
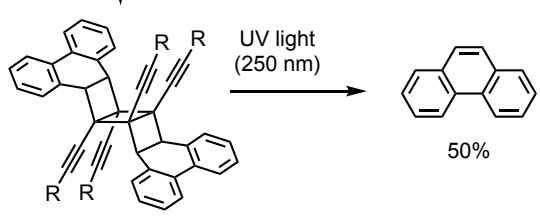

6, $100 \%(R=$ TIPS $)$

$[2+2]$ cyclo-
reversion $h v$

[ $\mathrm{R}$

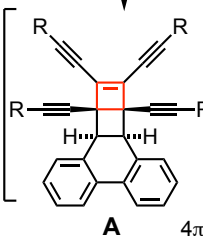

A

$4 \pi$ e disrotatory electrocyclic

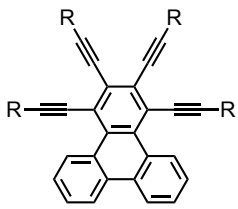

8, $96 \%$

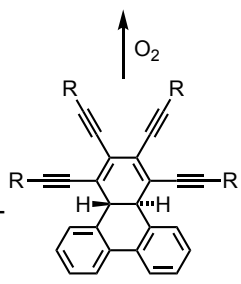

7, $50 \%$

$\uparrow \begin{gathered}6 \pi \mathrm{e} \\ \text { conrotatory }\end{gathered}$ $h v \quad \begin{aligned} & \text { electrocyclic } \\ & \text { ring closure }\end{aligned}$

b)
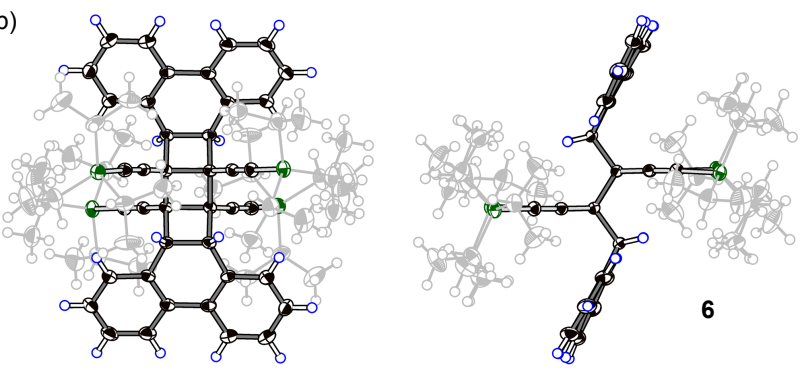

c)
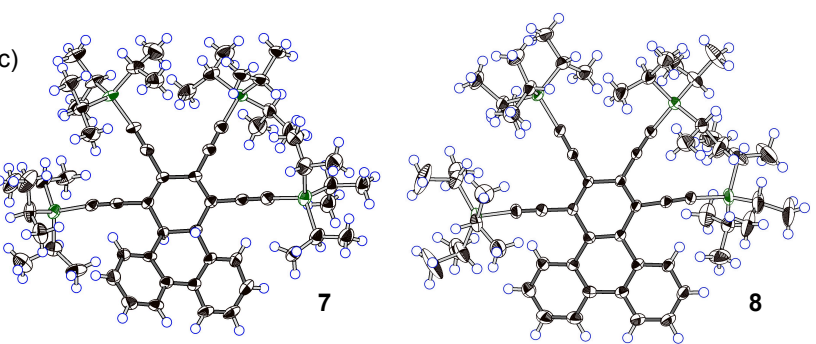

Figure 3. Reactivity of phenanthrene MAE model 2. a) Irradiation of 2 at $250 \mathrm{~nm}$ or $350 \mathrm{~nm}$, and irradiation of dimer 6 at $250 \mathrm{~nm}$, showing a possible mechanism for the formation of dihydrotriphenylene 7 ( $\mathrm{R}=$ TIPS). b) Two orthogonal views of the structure of 6 in the crystal. c) Structures of dihydrotriphenylene 7 and triphenylene 8. Thermal ellipsoids plotted at the $40 \%$ level for (b) and (c).

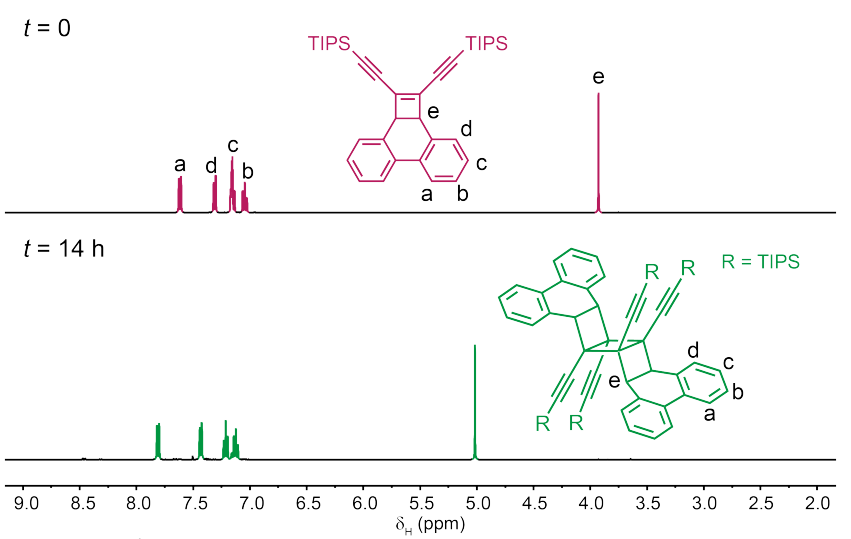

Figure 4. ${ }^{1} \mathrm{H}$ NMR spectra $\left(\mathrm{C}_{6} \mathrm{D}_{6}, 298 \mathrm{~K}, 400 \mathrm{MHz}\right)$ of a solution of 2 (red peaks) before and after irradiation with UV light (350 $\mathrm{nm}$, no purification). A [3]-ladderane 6 (green peaks) is formed quantitatively after irradiation for $14 \mathrm{~h}$. (The outcome of photolysis in $\mathrm{CDCl}_{3}$ is the same.)

The constitution of 7 was deduced from the fact that it is formed from 6 concomitantly with one equivalent of phenanthrene, and from the integration of the ${ }^{1} \mathrm{H}$ NMR signals. The crystal structure revealed that 7 has a surprising stereochemistry with a central trans-dihydrotriphenylene. ${ }^{30}$ This suggests that a photochemical domino reaction takes place after phenanthrene is extruded by a [2+2]-cycloreversion to form intermediate A (Figure 3a). This cyclobutene appears to undergo a disrotatory $4 \pi$ electrocyclic ring opening (photochemically allowed) to give a cyclohexadiene $\mathbf{B}$, which then undergoes a conrotatory $6 \pi$ electrocyclic ring opening (thermally allowed) to form a [10]annulene intermediate $\mathbf{C}$, which recloses via a disrotatory $6 \pi$ electrocyclic ring closure to yield 7 . Alternatively, the central cyclobutane ring in $\mathbf{A}$ may undergo a photochemical $[2+2]$-cycloreversion to generate $\mathbf{C}$ in one step. A similar cycloreversion was observed in the formation of [12] annulene from a ladderane. ${ }^{32}$

Intermediates $\mathbf{A}-\mathbf{C}$ have not been observed but these mechanisms appear to be the most likely explanation for the generation of 7 from $\mathbf{6}$. The crystal structure has four molecules of 7 in the asymmetric unit, all with essentially the same molecular geometry: a representative molecule is shown in Figure 3c.

When exposed to air, dihydrotriphenylene 7 is slowly oxidized to triphenylene $\mathbf{8}$ in the course of weeks. This process can be accelerated by stirring a $\mathrm{CH}_{2} \mathrm{Cl}_{2}$ solution under an oxygen atmosphere for five days to achieve full oxidation. The structure of 8 was confirmed by NMR, MS and X-ray crystallography (Figure 3c). ${ }^{30}$

Indane derivative $\mathbf{4}$ is a known compound, ${ }^{21 \mathrm{~d}}$ but its photochemistry has not been reported. We found that irradiation with $250 \mathrm{~nm}$ UV light leads to rapid formation of indane and triyne 5 (both in $70 \%$ yield; Figure 5 and 6). Competition experiments show that $\mathbf{4}$ reacts about five times faster than $\mathbf{2}$ under identical photolysis conditions. 

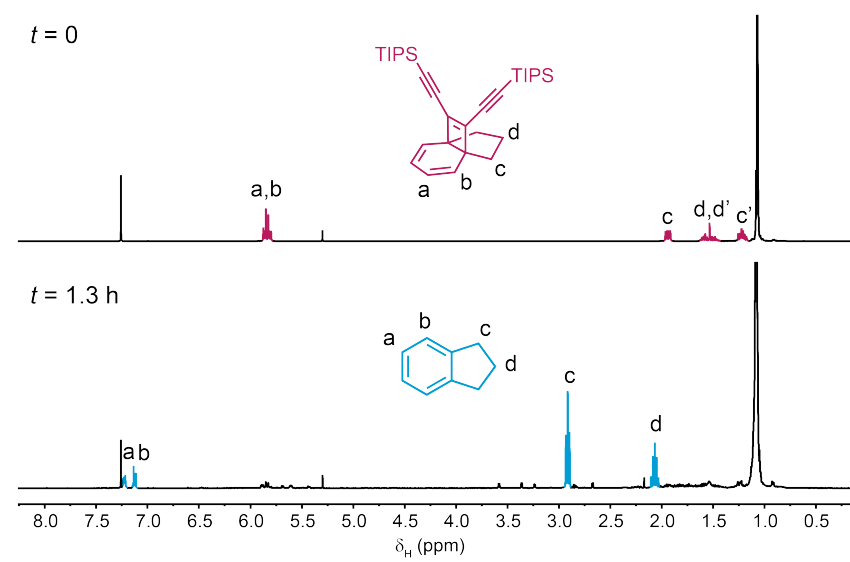

Figure 5. ${ }^{1} \mathrm{H}$ NMR spectra $\left(\mathrm{CDCl}_{3}, 298 \mathrm{~K}, 400 \mathrm{MHz}\right)$ of a solution of 4 (red peaks) before and after irradiation with UV light (250 nm, no purification). Indane (blue peaks) is formed in $70 \%$ yield after irradiation for $1.3 \mathrm{~h}$. The triyne 5 (formed in $70 \%$ yield) could be detected by ${ }^{13} \mathrm{C}$ NMR.

a)
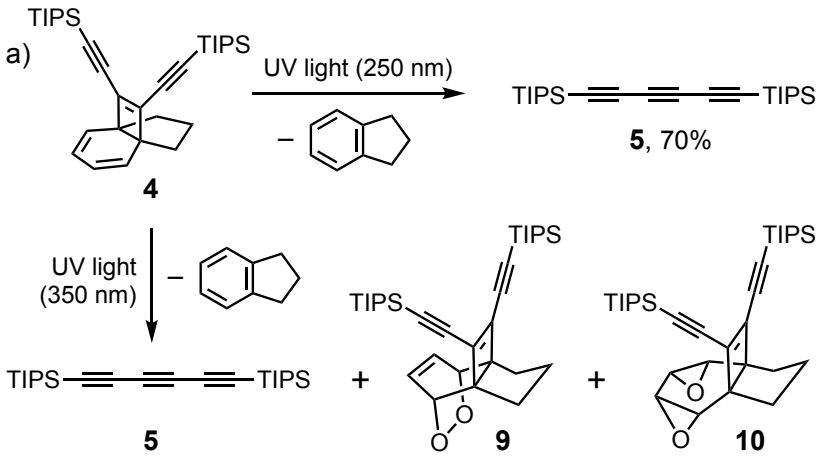

5
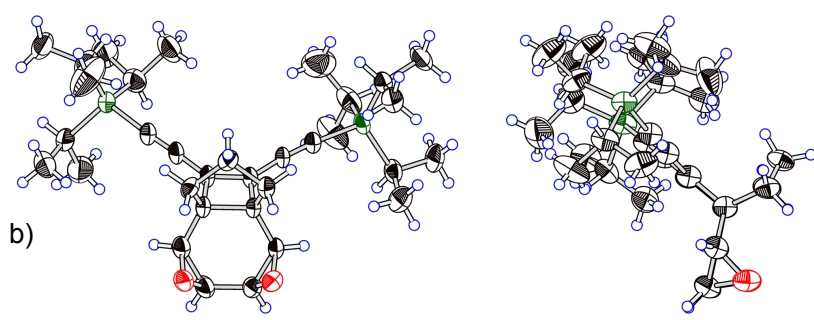

Figure 6. a) Reactivity of indane MAE model 4. b) Two orthogonal views of the structure of $\mathbf{1 0}$ in the crystal (thermal ellipsoids plotted at the $40 \%$ level).

In contrast to the clean photochemistry with $250 \mathrm{~nm}$ light, irradiation of indane 4 at $350 \mathrm{~nm}$ gives a complex mixture of products (Figures 6 and 7). Initially, a new set of ${ }^{1} \mathrm{H}$ resonances appears at $6.5 \mathrm{ppm}$ and $4.6 \mathrm{ppm}$ (green peaks in Figure 7); this set of peaks disappears to be replaced by another set of peaks at $3.6 \mathrm{ppm}$ and $3.2 \mathrm{ppm}$ (purple peaks in Figure 7). Formation of indane is also observed, indicating that unmasking occurs to some extent as well. The two products, 9 and 10, were isolated and characterized (isolated yields of 9 and 10 after $3.5 \mathrm{~h}$ of irradiation $19 \%$ and $28 \%$, respectively; $55 \%$ of $\mathbf{1 0}$ after $8 \mathrm{~h}$ of irradiation: ${ }^{1} \mathrm{H}$ NMR spectra shown in Figure $7 \mathrm{~b}$ ). The crystallographic structure determination of epoxide 10 (Figure $6 \mathrm{~b})^{30}$ enabled us to deduce the structure of peroxide 9. The reactions are summarized in Figure 6a. Presumably, traces of oxygen are converted to singlet oxygen and undergo hetero-Diels-Alder reaction ${ }^{33}$ with the diene moiety of 4. The formation of bis-epoxides from unsaturated endoperoxides has been reported previously. ${ }^{34}$ As expected, products 9 and $\mathbf{1 0}$ are not formed when rigorously $\mathrm{O}_{2}$-free solutions of $\mathbf{4}$ are irradiated. Tobe et al. reported the formation of a cyclooctatetraene and a semibullvalene (each in 7\% yield, using a low-pressure mercury lamp in hexane) when irradiating TMSand TBDMS-analogues of $4{ }^{21 \mathrm{~d}} \mathrm{We}$ also observed formation of these products, each in about $10 \%$ yield, when irradiating with $250 \mathrm{~nm}$ light, identified by their characteristic ${ }^{1} \mathrm{H}$ NMR spectra.

The crystal structure of $\mathbf{1 0}$ (Figure 6b) shows that the sixmembered cyclohexane-bisepoxide ring is remarkably flat (root-mean-squared deviation for 6 carbon atoms: $0.004 \AA$ ); this conformation has been reported previously in similar cyclohexane derivatives. ${ }^{35}$ Comparing the crystal structures of $\mathbf{2}$ and $\mathbf{1 0}$ reveals that the geometry of the enediyne unit is unaffected by the decoration of the other side of the cyclobutene ring; bond lengths and bonding angles are essentially identical.

In summary, both the indane and the phenanthrene group are viable MAEs for masking polyynes. Unmasking is quicker and more efficient for the indane but the phenanthrene MAE is more accessible. The alkyne masked with indane 4 gives triyne $\mathbf{5}$ in $70 \%$ yield; the one masked with phenanthrene 2 gives 5 in $20 \%$ yield.

\section{Rotaxane synthesis}

With these encouraging results in hand, we synthesized interlocked structures based on the phenanthrene and indane MAEs. Bulky trityl stoppers were added to ensure that the macrocycle cannot slip off after a rotaxane is formed. ${ }^{36}$ The synthesis of a phenanthrene rotaxane $\mathbf{1 6}$ and the corresponding reference thread $\mathbf{1 7}$ are shown in Schemes 2 and 3. 


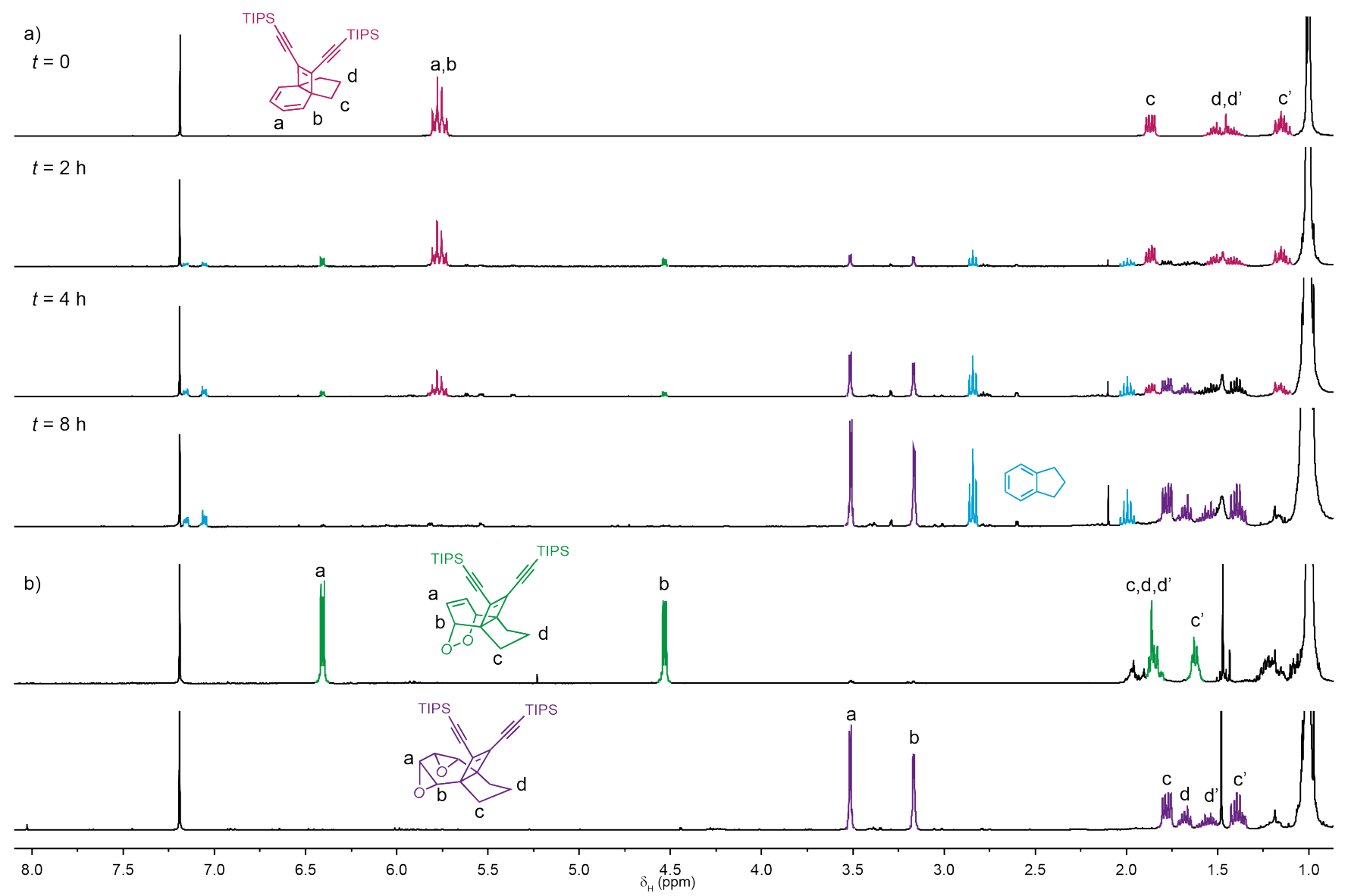

Figure 7. a) ${ }^{1} \mathrm{H}$ NMR spectra $\left(\mathrm{CDCl}_{3}, 298 \mathrm{~K}, 400 \mathrm{MHz}\right)$ of a solution of 4 (red peaks) before and after irradiation with UV light over 8 h. (350 nm, no purification). In addition to indane (blue peaks), two new species are formed (green and purple). b) ${ }^{1} \mathrm{H} \mathrm{NMR} \mathrm{spectra} \mathrm{(CDCl}{ }_{3}$, $298 \mathrm{~K}, 400 \mathrm{MHz}$ ) of the purified compounds; the green peaks are assigned to peroxide 9 and purple peaks belong to bisepoxide $\mathbf{1 0}$. 
Scheme 2. Synthesis of phenanthrene-masked rotaxane 16.

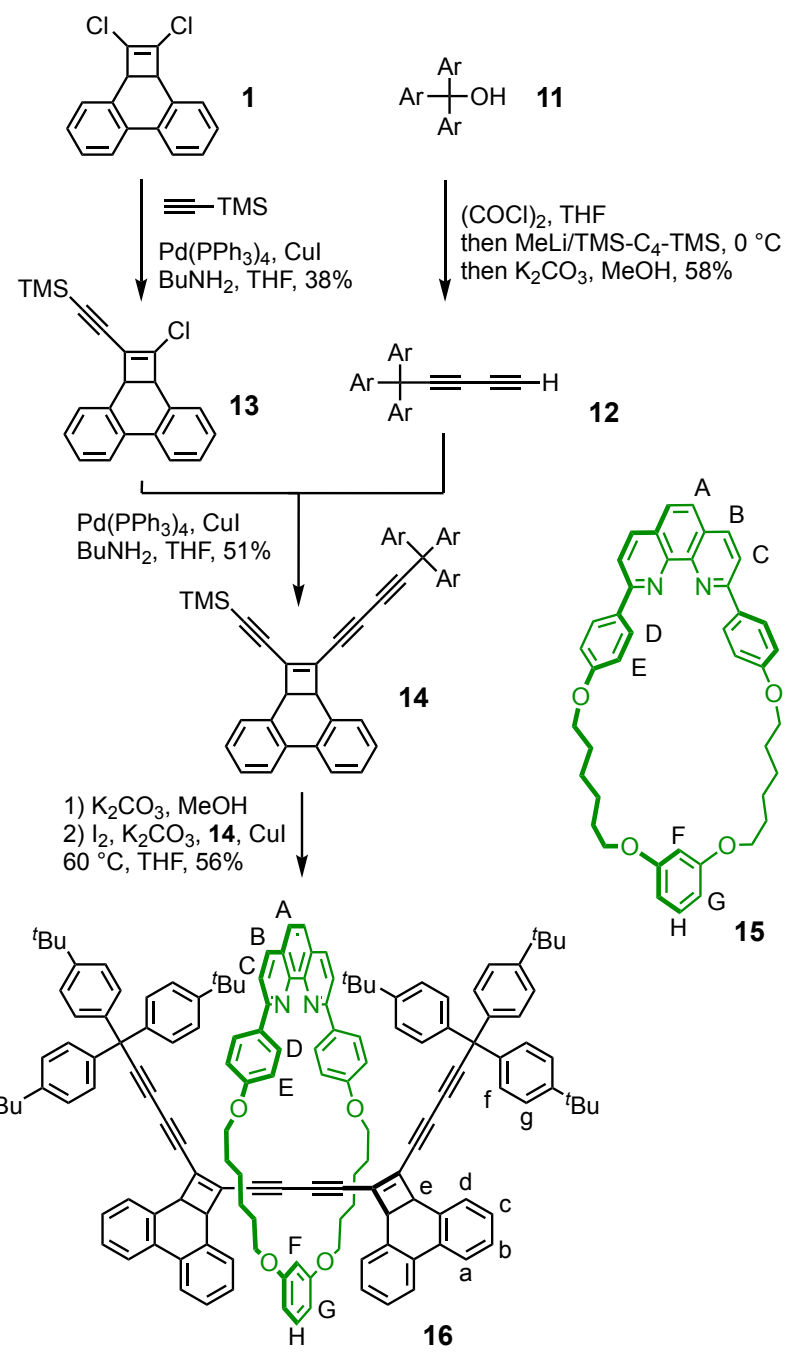

Synthesis of rotaxane $\mathbf{1 6}$ starts with desymmetrization of dichloride 1 via a Sonogashira coupling to TMS-acetylene to give chloride 13. In a subsequent Sonogashira coupling, diyne stopper 12 was installed to give stoppered masked phenanthrene $14(\mathrm{Ar}=4$-methylphenyl).

Stopper 12 was synthesized in one step from alcohol $\mathbf{1 1}^{36}$ We found that it is necessary to separate the trityl unit and the MAE by two acetylene units to prevent a steric clash of the stoppers in the rotaxane forming step. A design based on a single acetylene spacer between stopper and MAE failed to give interlocked products (SI, Scheme S5).

After TMS-deprotection of $\mathbf{1 4}$ with $\mathrm{K}_{2} \mathrm{CO}_{3} / \mathrm{MeOH}$, the phenanthrene rotaxane 16 was formed in 56\% yield via coppermediated oxidative homocoupling using macrocycle $15 .^{37}$
Scheme 3. Synthesis of phenanthrene reference thread 17.
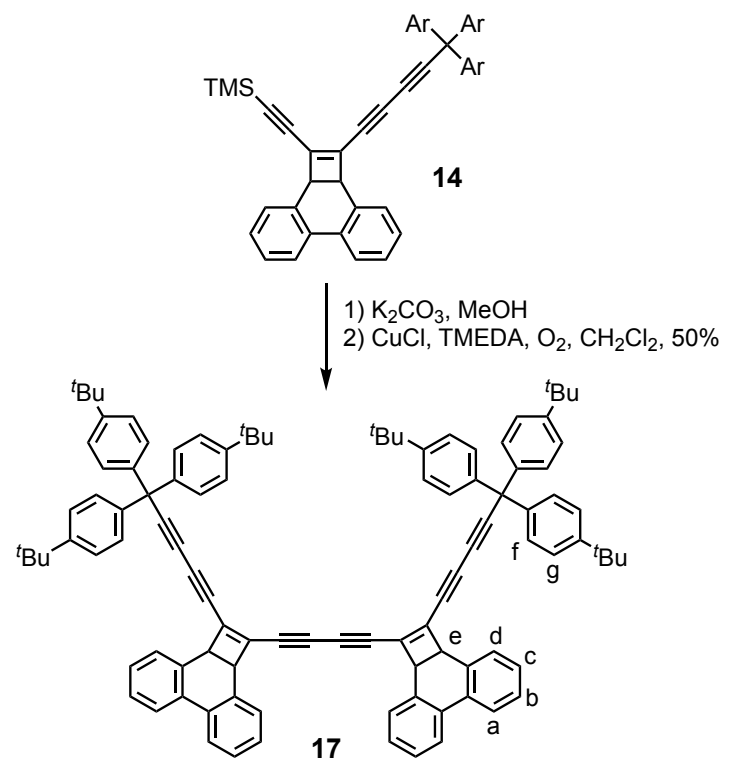

The synthesis of indane rotaxane 27 proved more challenging than anticipated. Sonogashira couplings using TMSacetylene instead of TIPS-acetylene are less efficient on dichloride 3 (53\% yield for TMS-acetylene, 100\% for TIPSacetylene). Therefore, initial attempts focused on TIPS protected derivatives. We were not able to couple stopper 12 to the indane 18 (Scheme 4) and TIPS indane stopper 21 could only be obtained by Cadiot-Chodkiewicz coupling ${ }^{12,38,39}$ to $\mathbf{2 0}$, the monodeprotected derivative of $\mathbf{4}$. Attempted deprotection of $\mathbf{2 1}$ to give $\mathbf{2 2}$ was not successful; a range of fluoride sources (TBAF, CsF, KF) led to rapid decomposition of $\mathbf{2 1}$ and analysis of the degradation products suggested that the trityl unit is cleaved from the molecule (Scheme S7). To overcome this problem, $\mathrm{SiEt}_{3}$ (TES) was used as a protecting group, as it does not require fluoride for deprotection. Surprisingly, the Cadiot-Chodkiewicz coupling, which yielded the TIPS analogue 21, did not work on 23. It is puzzling that changing the silyl protecting group (for a smaller one) in a remote part of the molecule has such a drastic effect on reactivity (Scheme 4). 
Scheme 4. Unsuccessful approaches to the synthesis of compound 22 .

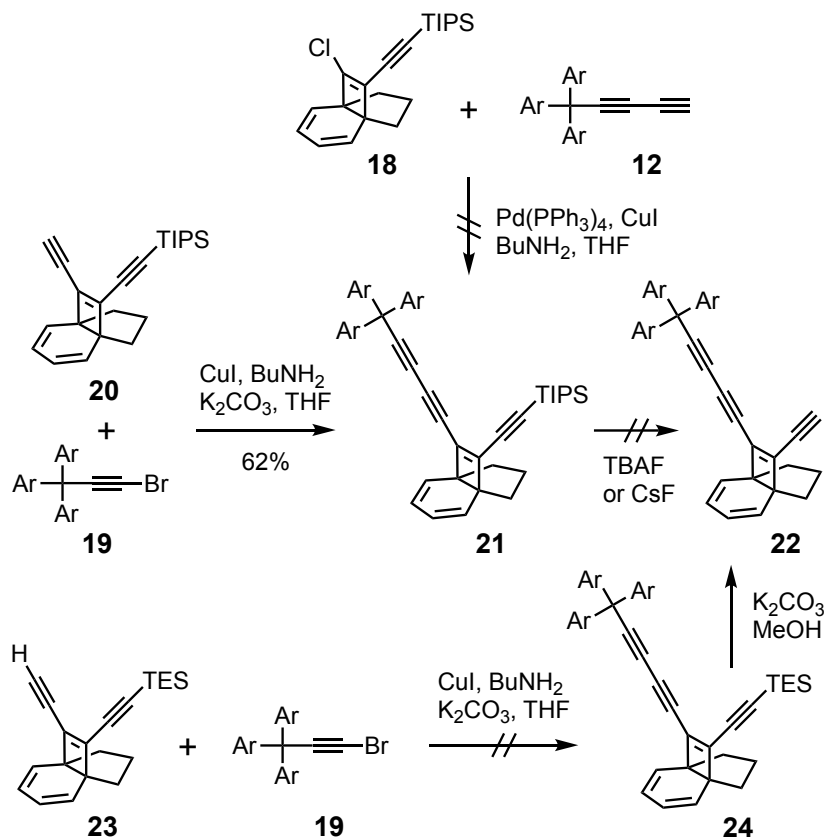

The successful route to $\mathbf{2 4}$ proceeds via a low-yielding Sonogashira coupling (15\%) to give 25 (Scheme 5). Subsequently a Sonogashira coupling gave $\mathbf{2 4}$ in $91 \%$ yield. In contrast to phenanthrene rotaxane $\mathbf{1 6}$, we were unable to prepare indane rotaxane 27 via a copper-mediated oxidative homocoupling; only non-interlocked products were obtained. However, if indane stopper $\mathbf{2 4}$ is deprotected to $\mathbf{2 2}$ and converted to the corresponding alkynyl bromide 26, rotaxane 27 can be formed in $47 \%$ yield (over three steps: TES-deprotection, bromination of half the material and Cadiot-Chodkiewicz coupling). ${ }^{12,39}$ Reference thread 29 was synthesized via a copper-catalyzed homocoupling (Scheme 6).

The ${ }^{1} \mathrm{H}$ NMR spectra of rotaxanes $\mathbf{1 6}$ and $\mathbf{2 7}$ are compared with those of the free threads $\mathbf{1 7}$ and $\mathbf{2 9}$, and macrocycle 15, in Figure 8. Compounds 16, 17, 27 and 29 exist as mixtures of meso and racemic diastereomers (SI, Scheme S8), causing splittings in the NMR resonances. The splittings in the signals of the phenanthroline macrocycle are more pronounced in $\mathbf{1 6}$, compared to 27; this can be attributed to the higher magnetic anisotropy and greater lateral extension of the phenanthrene group compared to the indane. In both rotaxanes, NOEs were observed between the aryl protons of the stopper ( $\mathrm{f}$ and $\mathrm{g}$ in 16, e and $f$ in 27) and proton A of macrocycle 15, indicating that the macrocycle can shuttle over the MAE units. The identity of rotaxanes was further confirmed by mass spectrometry; in contrast to the hydrocarbon precursors and dumbbells, all rotaxanes can be detected easily using ESI-MS (see SI for MS spectra).

Scheme 5. Synthesis of rotaxane 28 .
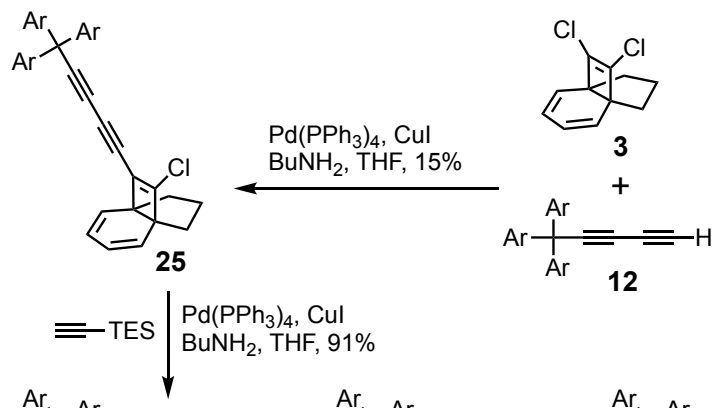

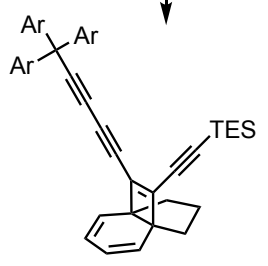

24

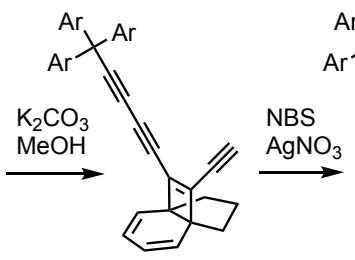

22
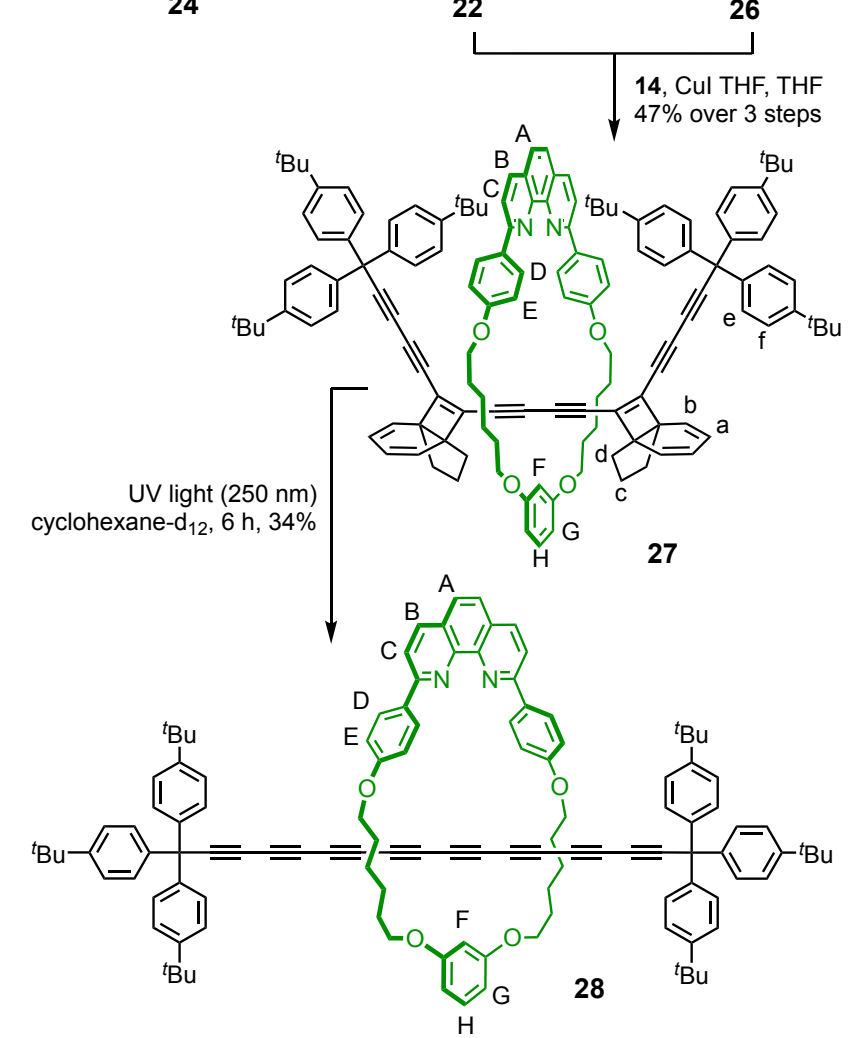
Scheme 6. Synthesis of dumbbell 30.
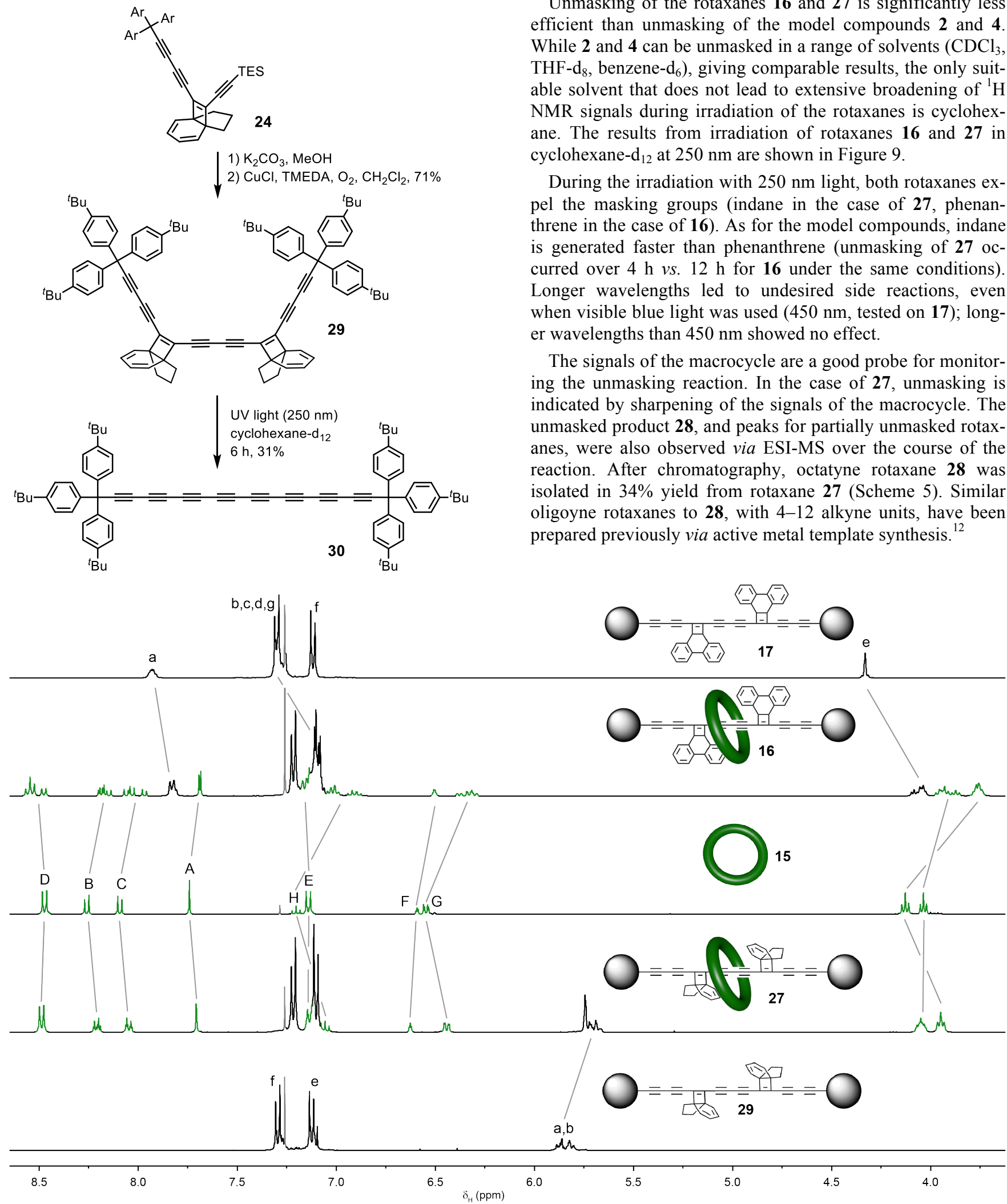

Figure 8. Comparison of the ${ }^{1} \mathrm{H}$ NMR spectra $\left(\mathrm{CDCl}_{3}, 298 \mathrm{~K}, 500 \mathrm{MHz}\right)$ of phenanthrene thread 17, phenanthrene rotaxane 16, macrocycle 15, indane rotaxane 27, and indane thread 29. Signal labeling according to Schemes 2 and 5. Signals from the macrocycle are highlighted in green.

\section{Photochemical unmasking of polyyne rotaxanes}

Unmasking of the rotaxanes $\mathbf{1 6}$ and $\mathbf{2 7}$ is significantly less efficient than unmasking of the model compounds 2 and 4. While $\mathbf{2}$ and $\mathbf{4}$ can be unmasked in a range of solvents $\left(\mathrm{CDCl}_{3}\right.$, THF- $d_{8}$, benzene- $d_{6}$ ), giving comparable results, the only suitable solvent that does not lead to extensive broadening of ${ }^{1} \mathrm{H}$ NMR signals during irradiation of the rotaxanes is cyclohexane. The results from irradiation of rotaxanes $\mathbf{1 6}$ and $\mathbf{2 7}$ in cyclohexane- $d_{12}$ at $250 \mathrm{~nm}$ are shown in Figure 9.

During the irradiation with $250 \mathrm{~nm}$ light, both rotaxanes expel the masking groups (indane in the case of 27, phenanthrene in the case of 16). As for the model compounds, indane is generated faster than phenanthrene (unmasking of $\mathbf{2 7}$ occurred over $4 \mathrm{~h}$ vs. $12 \mathrm{~h}$ for $\mathbf{1 6}$ under the same conditions). Longer wavelengths led to undesired side reactions, even when visible blue light was used (450 $\mathrm{nm}$, tested on 17); longer wavelengths than $450 \mathrm{~nm}$ showed no effect.

The signals of the macrocycle are a good probe for monitoring the unmasking reaction. In the case of $\mathbf{2 7}$, unmasking is indicated by sharpening of the signals of the macrocycle. The unmasked product $\mathbf{2 8}$, and peaks for partially unmasked rotaxanes, were also observed via ESI-MS over the course of the reaction. After chromatography, octatyne rotaxane $\mathbf{2 8}$ was isolated in 34\% yield from rotaxane 27 (Scheme 5). Similar oligoyne rotaxanes to $\mathbf{2 8}$, with 4-12 alkyne units, have been prepared previously via active metal template synthesis. ${ }^{12}$ 

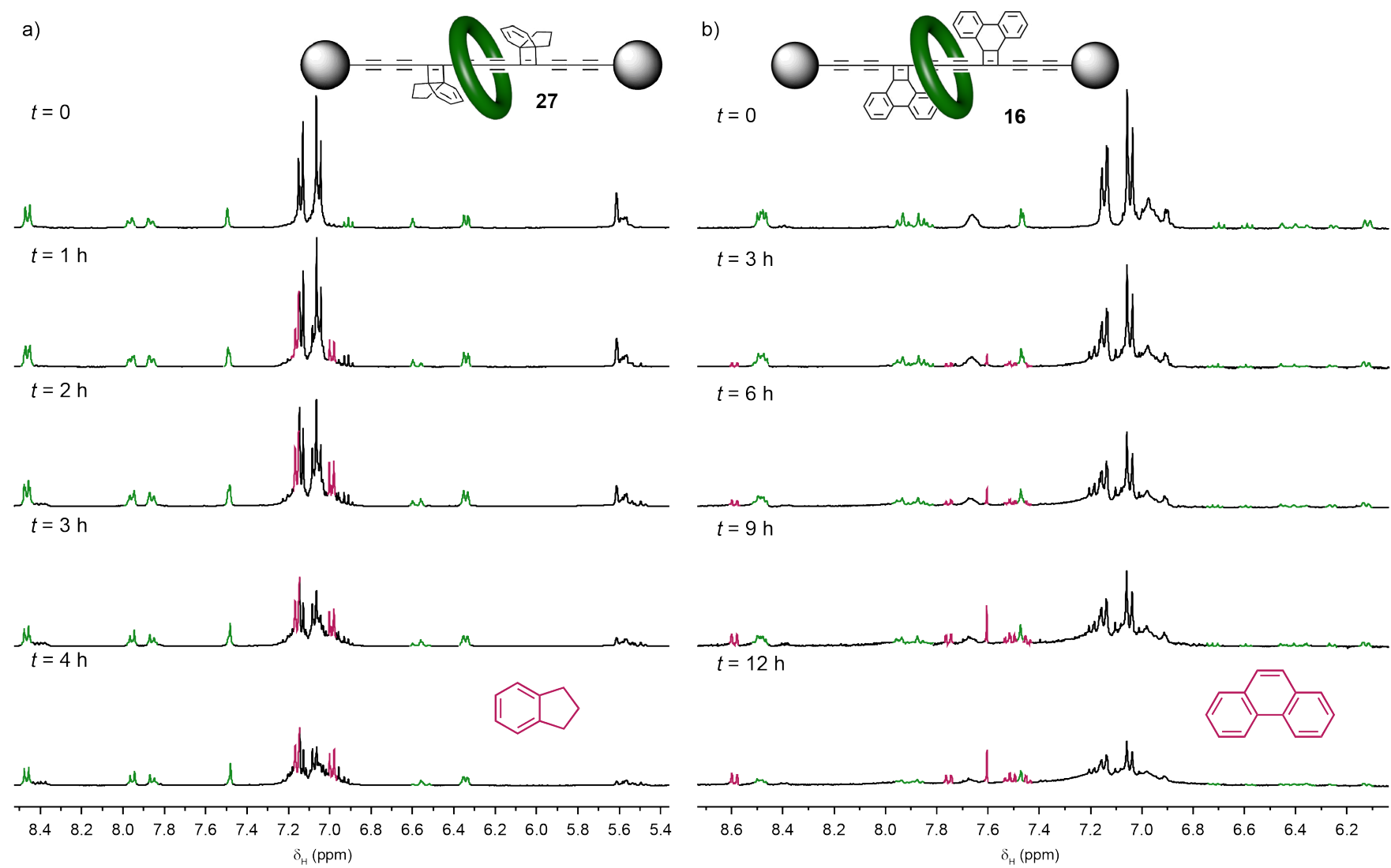

Figure 9. Unmasking of rotaxanes 16 and 27. a) ${ }^{1} \mathrm{H}$ NMR spectra (cyclohexane-d ${ }_{12}, 298 \mathrm{~K}, 400 \mathrm{MHz}$ ) of a solution of 27 before and after irradiation $(250 \mathrm{~nm}$ ) for $4 \mathrm{~h}$. Green peaks are assigned to the macrocycle; red peaks to indane. Green peaks sharpen over time, indicating a higher symmetry. Unmasked octayne rotaxane 28 was isolated from the reaction mixture (34\% yield). b) ${ }^{1} \mathrm{H}$ NMR spectra (cyclohexane$\left.\mathrm{d}_{12}, 298 \mathrm{~K}, 400 \mathrm{MHz}\right)$ of a solution of 16 before and after irradiation $(250 \mathrm{~nm})$ for $12 \mathrm{~h}$. Green peaks are assigned to the macrocycle; red peaks to phenanthrene. Phenanthrene is generated in the course of the reaction, but the macrocycle peaks broaden and lose intensity due to decomposition. No unmasked rotaxane $\mathbf{2 8}$ was isolated from the photolysis of $\mathbf{1 6}$.

Sharpening of the macrocycle peaks does not occur on irradiation of phenanthrene rotaxane 16 (Figure 9b); all peaks belonging to the rotaxane broaden significantly and lose intensity, in spite of the release of phenanthrene. ESI-MS shows no new peaks, only the peak for starting material 16 (intensity decreases over time) was observed. No identifiable products could be isolated from photolysis of $\mathbf{1 6}$.

As a reference, we synthesized the corresponding octayne dumbbell 30 by irradiating indane thread 29 with UV light $(250 \mathrm{~nm})$ : the yield $(31 \%)$ is similar to the unmasking of rotaxane 27 (Scheme 6). The ${ }^{1} \mathrm{H}$ NMR spectra of indane rotaxane $\mathbf{2 7}$, unmasked rotaxane $\mathbf{2 8}$, macrocycle $\mathbf{1 5}$ and unmasked thread $\mathbf{3 0}$ are compared in Figure 10. No strong NOEs are observed between the stopper units and the macrocycle of $\mathbf{2 8}$, suggesting that the macrocycle resides near the center of the polyyne chain.

\section{CONCLUSIONS}

We have shown that MAEs can be successfully applied to make long polyyne rotaxanes. The unmasking reaction of two different MAEs was thoroughly studied and unexpected photochemical side products were identified by X-ray crystallography. The indane-based MAE developed by Tobe and coworkers can be unmasked yielding a polyyne rotaxane comprising eight $-\mathrm{C} \equiv \mathrm{C}$ - units, whereas the phenanthrene MAE proved to be unsuitable, due to competing side reactions during photochemical unmasking. This is the first demonstration that a polyyne can be released from a masked interlocked precursor. Our results indicate that encapsulated versions of carbyne and cyclocarbons should be accessible, but to achieve this objective, it will be necessary to use a smaller macrocycle (or increase the bulk of the MAE), so that the MAE groups act as temporary stoppers. 


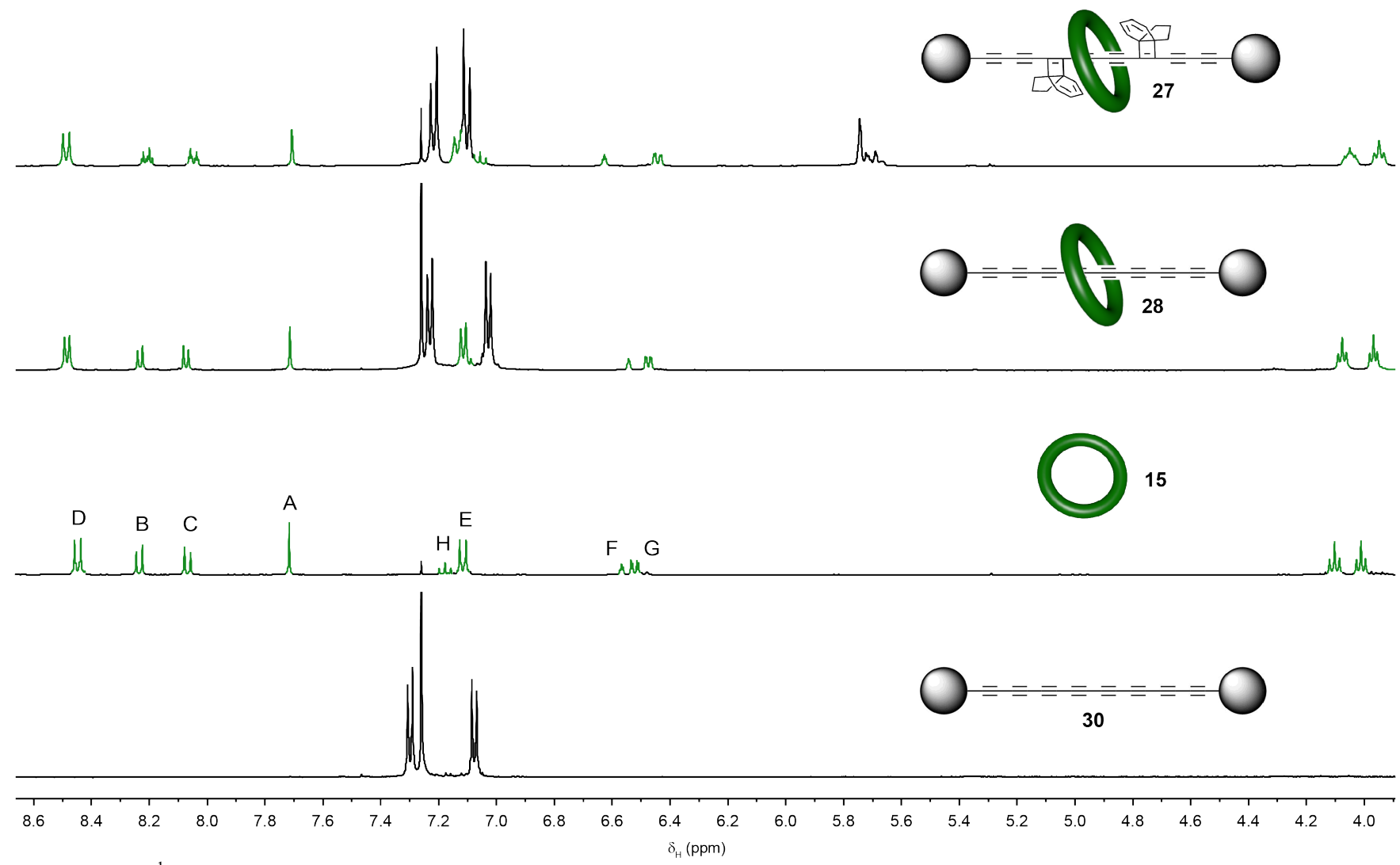

Figure 10. a) ${ }^{1} \mathrm{H}$ NMR spectra $\left(\mathrm{CDCl}_{3}, 298 \mathrm{~K}, 500 \mathrm{MHz}\right)$ of masked indane rotaxane 27, unmasked octayne rotaxane 28, free macrocycle 15 and unmasked thread 30. Signals numbered according to Scheme 5 . The shifts of macrocycle $\mathbf{1 5}$ are hardly affected by the threaded dumbbell in rotaxane $\mathbf{2 8}$.

\section{ASSOCIATED CONTENT}

\section{Supporting Information}

The Supporting Information is available free of charge at https://pubs.acs.org/doi/10.1021/jacsXXXXXXX.

Details of synthetic protocols, copies of NMR and MS spectra, crystallographic data (PDF).

Crystallographic data for compound 2 (2003495) (CIF)

Crystallographic data for compound 6 (2003496) (CIF)

Crystallographic data for compound 7 (2003497) (CIF)

Crystallographic data for compound 8 (2003498) (CIF)

Crystallographic data for compound 10 (2003499) (CIF)

\section{AUTHOR INFORMATION}

\section{Corresponding Author}

*harry.anderson@chem.ox.ac.uk

\section{ACKNOWLEDGMENT}

We thank Prof. Yoshito Tobe for providing us with a sample of dichloride 3, Lorel M. Scriven for providing us with a sample of macrocycle 15, and the Leverhulme Trust for funding. P.G. acknowledges receipt of Postdoc.Mobility fellowships from the Swiss National Science Foundation (P300P2 177829). We acknowledge Diamond Light Source for time on Beamline I19 under Proposal MT20876.

\section{REFERENCES}

(1) Diederich, F. Carbon Scaffolding: Building Acetylenic AllCarbon and Carbon-Rich Compounds. Nature 1994, 369, 199-207.

(2) (a) Chalifoux, W. A.; Tykwinski, R. R. Synthesis of Extended Polyynes: Toward Carbyne. Comptes Rendus Chim. 2009, 12, 341-
358. (b) Tykwinski, R. R. Carbyne: The Molecular Approach. Chem. Rec. 2015, 15, 1060-1074. (c) Casari, C. S.; Tommasini, M.; Tykwinski, R. R.; Milani, A. Carbon-atom wires: 1-D systems with tunable properties, Nanoscale 2016, 8, 4414-4435. (d) Casari, C. S.; Milani, A. Carbyne: From the Elusive Allotrope to Stable Carbon Atom Wires. MRS Commun. 2018, 8, 207-219.

(3) (a) Kertesz, M.; Koller, J.; Azman, A. Ab initio Hartree-Fock crystal orbital studies. II. Energy bands of an infinite carbon chain. $J$. Chem. Phys. 1978, 68, 2779-2782. (b) Tongay, S.; Senger, R. T.; Dag, S.; Ciraci, S. Ab-initio Electron Transport Calculations of Carbon Based String Structures. Phys. Rev. Lett. 2004, 93, 136404. (c) Yang, S.; Miklos Kertesz, M. Bond Length Alternation and Energy Band Gap of Polyyne. J. Phys. Chem. A 2006, 110, 9771-9774. (d) Zanolli, Z.; Onida, G.; Charlier, J.-C. Quantum Spin Transport in Carbon Chains. ACS Nano 2010, 4, 5174-5180.

(4) Liu, M.; Artyukhov, V. I.; Lee, H.; Xu, F.; Yakobson, B. I. Carbyne from First Principles: Chain of C Atoms, a Nanorod or a Nanorope. ACS Nano 2013, 7, 10075-10082.

(5) Tarakeshwar, P.; Buseck, P. R.; Kroto, H. W. Pseudocarbynes: Charge-Stabilized Carbon Chains. J. Phys. Chem. Lett. 2016, 7, $1675-1681$

(6) Hoye, T. R.; Baire, B.; Niu, D.; Willoughby, P. H.; Woods, B. P. The Hexadehydro-Diels-Alder Reaction. Nature 2012, 490, 208211.

(7) (a) Schrettl, S.; Stefaniu, C.; Schwieger, C.; Pasche, G.; Oveisi, E.; Fontana, Y.; Fontcuberta i Morral, A.; Reguera, J.; Petraglia, R.; Corminboeuf, C.; Brezesinski, G.; Frauenrath, H. Functional carbon nanosheets prepared from hexayne amphiphile monolayers at room temperature. Nat. Chem. 2014, 6, 468-467. (b) Chernick, E. T.; Tykwinski, R. R. Carbon-rich nanostructures: the conversion of acetylenes into materials. J. Phys. Org. Chem. 2013, 26, 742-749.

(8) Zhang, Y.; Su, Y.; Wang, L.; Kong, E. S.-W.; Chen, X.-S.; Zhang, Y. A one-dimensional extremely covalent material: monatomic carbon linear chain. Nanoscale Res. Lett. 2011, 6, 577. 
(9) Chalifoux, W.; Tykwinski, R. Synthesis of Polyynes to Model the sp-Carbon Allotrope Carbyne. Nat. Chem. 2010, 2, 967-971.

(10) (a) Pigulski, B.; Gulia, N.; Szafert, S. Reactivity of Polyynes: Complex Molecules from Simple Carbon Rods. Eur. J. Org. Chem. 2019, 1420-1445. (b) Jevic, M.; Nielsen, M. B. Synthetic Strategies for Oligoynes. Asian J. Org. Chem. 2015, 4, 286-295.

(11) Schrettl, S.; Contal, E.; Hoheisel, T.; Fritzsche, M.; Balog, S.; Szilluweit, R.; Frauenrath, H. Facile synthesis of oligoyne amphiphiles and their rotaxanes. Chem. Sci. 2015, 6, 564-574.

(12) Movsisyan, L. D.; Franz, M.; Hampel, F.; Thompson, A. L.; Tykwinski, R. R.; Anderson, H. L. Polyyne Rotaxanes: Stabilization by Encapsulation. J. Am. Chem. Soc. 2016, 138, 1366-1376.

(13) Stahl, J.; Bohling, J. C.; Bauer, E. B.; Peters, T. B.; Mohr, W.; Martín-Alvarez, J. M.; Hampel, F.; Gladysz, J. A. sp Carbon Chains Surrounded by sp ${ }^{3}$ Carbon Double Helices: A Class of Molecules that are Accessible by Self-Assembly and Models for "Insulated" Molecular-Scale Devices. Angew. Chem. Int. Ed. 2002, 41, 1871-1876.

(14) Taylor, T. J.; Gabbaï, F. P. Supramolecular Stabilization of $\alpha, \omega$-Diphenylpolyynes by Complexation to the Tridentate Lewis Acid $\left[o-\mathrm{C}_{6} \mathrm{~F}_{4} \mathrm{Hg}\right]_{3}$. Organometallics 2006, 25, 2143-2147.

(15) (a) Zhao, X. L.; Ando, Y.; Liu, Y.; Jinno, M.; Suzuki, T. Carbon nanowire made of a long linear carbon chain inserted inside a multiwalled carbon nanotube. Phys. Rev. Lett. 2003, 90, 187401. (b) Zhao, C.; Kitaura, R.; Hara, H.; Irle, S.; Shinohara, H. Growth of Linear Carbon Chains inside Thin Double-Wall Carbon Nanotubes. $J$. Phys. Chem. C 2011, 115, 13166-13170. (c) Shi, L.; Rohringer, P.; Suenaga, K.; Niimi, Y.; Kotakoski, J.; Meyer, J. C.; Peterlik, H.; Wanko, M.; Cahangirov, S.; Rubio, A.; Lapin, Z. J.; Novotny, L.; Ayala, P.; Pichler, T. Confined linear carbon chains as a route to bulk carbyne. Nat. Mater 2016, 15, 634-640.

(16) Frampton, M. J.; Anderson, H. L. Insulated Molecular Wires. Angew. Chem. Int. Ed. 2007, 46, 1028-1064.

(17) Saito, S.; Takahashi, E.; Nakazono, K. Synthesis of [2]Rotaxanes by the Catalytic Reactions of a Macrocyclic Copper Complex. Org. Lett. 2006, 8, 5133-5136.

(18) Berná, J.; Crowley, J. D.; Goldup, S. M.; Hänni, K. D.; Lee, A.-L.; Leigh, D. A. A Catalytic Palladium Active-Metal Template Pathway to [2]Rotaxanes. Angew. Chem., Int. Ed. 2007, 46, 57095713.

(19) (a) Weisbach, N.; Baranová, Z.; Gauthier, S.; Reibenspies, J. H.; Gladysz, J. A. A New Type of Insulated Molecular Wire: A Rotaxane Derived from a Metal-Capped Conjugated Tetrayne. Chem. Commun. 2012, 48, 7562-7564. (b) Sahnoune, H.; Baranová, Z.; Bhuvanesh, N.; Gladysz, J. A.; Halet, J. F. A Metal-Capped Conjugated Polyyne Threaded through a Phenanthroline-Based Macrocycle. Probing beyond the Mechanical Bond to Interactions in Interlocked Molecular Architectures. Organometallics 2013, 32, 6360-6367. (c) Baranová, Z.; Amini, H.; Bhuvanesh, N.; Gladysz, J. A. Rotaxanes Derived from Dimetallic Polyynediyl Complexes: Extended Axles and Expanded Macrocycles. Organometallics 2014, 33, 6746-6749.

(20) Movsisyan, L. D.; Kondratuk, D. V.; Franz, M.; Thompson, A. L.; Tykwinski, R. R.; Anderson, H. L. Synthesis of Polyyne Rotaxanes. Org. Lett. 2012, 14, 3424-3426.

(21) (a) Tobe, Y.; Fujii, T.; Naemura, K. Photochemical Method for Generation of Linear Polyynes: [2+2] Cycloreversion of [4.3.2]Propellatrienes Extruding Indan. J. Org. Chem 1994, 59, 12361237. (b) Tobe, Y.; Fujii, T.; Matsumoto, H.; Naemura, K.; Achiba, Y.; Wakabayashi, T. A New Entry into Cyclo[n]carbons: [2+2] Cycloreversion of Propellane-Annelated Dehydroannulenes. J. Am. Chem. Soc. 1996, 118, 2758-2759. (c) Tobe, Y.; Matsumoto, H.; Naemura, K.; Achiba, Y.; Wakabayashi, T. Generation of Cyclocarbons with $4 n$ Carbon Atoms $\left(\mathrm{C}_{12}, \mathrm{C}_{16}\right.$, and $\left.\mathrm{C}_{20}\right)$ by [2+2] Cycloreversion of Propellane-Annelated Dehydroannulenes. Angew. Chem. Int. Ed. Engl. 1996, 35, 1800-1802. (d) Tobe, Y.; Fujii, T.; Matsumoto, H.; Tsumuraya, K.; Noguchi, D.; Nakagawa, N.; Sonoda, M.; Naemura, K; Achiba, Y. Wakabayashi, T. [2+2] Cyclorevision of [4.3.2]Propella-1,3,11-trienes: An Approach to Cyclo[ $n]$ carbons from Propellane-Annelated Dehydro[ $n]$ annulenes. J. Am. Chem. Soc. 2000, 122, 1762-1775. (e) Tobe, Y.; Nakagawa, N.; Kishi, J.; Sonoda, M.; Naemura, K.; Wakabayashi, T.; Shida, T.; Achiba, Y. Polyyne Cyclization to Form Carbon Cages:
[16.16.16] $(1,3,5)$ cyclophanetetracosayne derivatives $\mathrm{C}_{60} \mathrm{H}_{6}$ and $\mathrm{C}_{60} \mathrm{Cl}_{6}$ as Precursors to $\mathrm{C}_{60}$ Fullerene. Tetrahedron 2001, 57, 3629-3636. (f) Tobe, Y.; Furukawa, R.; Sonoda, M.; Wakabayashi, T. [12.12]Paracyclophanedodecaynes $\mathrm{C}_{36} \mathrm{H}_{8}$ and $\mathrm{C}_{36} \mathrm{Cl}_{8}$ : The Smallest Paracyclophynes and Their Transformation into the Carbon Cluster Ion $\mathrm{C}_{36}{ }^{-}$. Angew. Chem. Int. Ed. 2001, 40, 4072-4074. (g) Tobe, Y.; Kishi, J.; Ohki, I; Sonoda, M. Facile Intramolecular Cyclization in Oxidative Coupling of Acetylenes Linked to 1,3-Positions of Benzene: Strained [12]Metacyclophanedienetetrayne System. J. Org. Chem. 2003, 68, 3330-3332.

(22) Tobe, Y.; Umeda, R.; Iwasa, N.; Sonoda, M. Expanded Radialenes with Bicyclo[4.3.1]Decatriene Units: New Precursors to $\mathrm{Cy}-$ clo $[n]$ Carbons. Chem. Eur. J. 2003, 9, 5549-5559.

(23) Zecher, D. C.; West, R. Synthesis of a Diquinocyclopropanone and a Diquinoethylene. J. Am. Chem. Soc. 1967, 89, 153-155.

(24) (a) Rubin, Y.; Diederich, F. Precursors to the Cyclo[n]carbons: $[4 n+2]-$ and $[4 n]$ Annulenes with Unusual Stabilities. $J$. Am. Chem. Soc. 1989, 111, 6870-6871. (b) Rubin, Y.; Knobler, C. B.; Diederich, F. Precursors to the cyclo[ $n]$ carbons: from 3,4-Dialkynyl3-Cyclobutene-1,2-diones and 3,4-dialkynyl-3-cyclobutene-1,2-diols to cyclobutenodehydroannulenes and higher oxides of carbon. J. Am. Chem. Soc. 1990, 112, 1607-1617. (c) Rubin, Y.; Kahr, M.; Knobler, C. B.; Diederich, F.; Wilkins, C. L. The Higher Oxides of Carbon $\mathrm{C}_{8 n} \mathrm{O}_{2 n}(n=3-5)$ : Synthesis, Characterization, and X-Ray Crystal Structure. Formation of Cyclo[ $[n]$ carbon Ions $\mathrm{C}_{n}^{+}(n=18,24), \mathrm{C}_{n}^{-}(n$ $=18,24,30)$, and Higher Carbon Ions Including $\mathrm{C}_{60}{ }^{+}$in Laser Desorption Fourier Transform Mass Spectrometric Experiments. J. Am. Chem. Soc. 1991, 113, 495-500. (d) K. Kaiser, L. M. Scriven, F. Schulz, P. Gawel, L. Gross, H. L. Anderson, An sp-hybridized molecular carbon allotrope, cyclo[18]carbon. Science 2019, 365, 12991301.

(25) Diederich, F.; Rubin, Y.; Knobler, C. B.; Whetten, R. L.; Schriver, K. E.; Houk, K. N.; Li, Y. All-Carbon Molecules: Evidence for the Generation of Cyclo[18]carbon from a Stable Organic Precursor. Science. 1989, 245, 1088-1090.

(26) (a) Rubin, Y.; Knobler, C. B.; Diederich, F. Synthesis and Crystal Structure of a Stable Hexacobalt Complex of $\mathrm{Cy}$ clo[18]carbon. J. Am. Chem. Soc. 1990, 112, 4966-4968. (b) Lewis, J.; Lin, B.; Khan, M. S.; Al-Mandhary, M. R. A.; Raithby, P. R. Synthesis and Structural Characterization of Cobalt Complexes Derived from Conjugated Tetraynes. J. Organomet. Chem. 1994, 484, 161167. (c) Haley, M. M.; Langsdorf, B. L. Cyclophyne chemistry: synthesis and study of an octacobalt complex of [8.8]paracyclophaneoctayne. Chem. Commun. 1997, 1121-1122. (d) Kohn, D. R.; Gawel, P.; Xiong, Y.; Christensen, K. E.; Anderson, H. L. Synthesis of Polyynes Using Dicobalt Masking Groups. J. Org. Chem. 2018, 83, 2077-2086.

(27) Adamson, G. A.; Rees, C. W. Towards the Total Synthesis of Cyclo $[n]$ carbons and the Generation of Cyclo[6]carbon. J. Chem. Soc., Perkin Trans. 1 1996, 1535-1543.

(28) (a) Eisler, S.; Tykwinski, R. R. Migrating Alkynes in Vinylidene Carbenoids: An Unprecedented Route to Polyynes. J. Am. Chem. Soc. 2000, 122, 10736-10737. (b) Luu, T.; Morisaki, Y.; Cunningham, N.; Tykwinski, R. R. One-Pot Formation and Derivatization of Di- and Triynes Based on the Fritsch-Buttenberg-Wiechell Rearrangement. J. Org. Chem. 2007, 72, 9622-9629.

(29) Hacker, N. P.; McOmie, J. F. W. Synthesis of Cyclobuta[1]phenanthrene Derivatives from [2+2]photoadducts of Chlorinated Ethenes and Phenanthrene. Tetrahedron 1984, 40, 5249-5254.

(30) Raw-frame X-ray crystallographic data were reduced using CrysAlisPro and the structures were solved using 'Superflip' [Palatinus, L.; Chapuis, G. SUPERFLIP - a computer program for the solution of crystal structures by charge flipping in arbitrary dimensions. $J$. Appl. Cryst. 2007, 40, 786-790] before refinement with CRYSTALS [(a) Parois, P.; Cooper, R. I.; Thompson, A. L. Crystal structures of increasingly large molecules: meeting the challenges with CRYSTALS software. Chem. Cent. J. 2015, 9, 30. (b) Cooper, R. I.; Thompson, A. L.; Watkin, D. J. J. Appl. Cryst. 2010, 43, 1100-1107] as per the SI (CIF). Full refinement details are given in the Supporting Information (CIF); crystallographic data have been deposited with the 
Cambridge Crystallographic Data Centre (CCDC 2003495-99) and can be obtained via www. ccdc.cam.ac.uk/data_request/cif.

(31) (a) Warrener, R. N.; Abbenante, G.; Kennard, C. H. L. A tandem cycloaddition protocol for the controlled synthesis of [n]ladderanes: new rods and spacers. J. Am. Chem. Soc. 1994, 116, 3645-3646. (b) Hopf, H.; Greiving, H.; Jones, P. G.; Bubenitschek, P. Topochemical reaction control in solution. Angew. Chem. Int. Ed. Engl. 1995, 34, 685-687. (c) Mascitti, V.; Corey, E. J. Enantioselective Synthesis of Pentacycloanammoxic Acid. J. Am. Chem. Soc. 2006, 128, 3118-3119. (d) Mercer, J. A. M.; Cohen, C. M.; Shuken, S. R.; Wagner, A. M.; Smith, M. W.; Moss, III, F. R.; Smith, M. D.; Vahala, R.; Gonzalez-Martinez, A.; Boxer, S. G.; Burns, N. Z. Chemical synthesis and self-assembly of a ladderane phospholipid, J. Am. Chem. Soc. 2016, 138, 15845-15848.

(32) Oth, J. F. M.; Röttele, H.; Schröder, G. [12]Annulene. Tetrahedron Lett. 1970, 11, 61-66.

(33) Leach, A. G.; Houk, K. N. Diels-Alder and Ene Reactions of Singlet Oxygen, Nitroso Compounds and Triazolinediones: Transition States and Mechanisms from Contemporary Theory. Chem. Commun. 2002, 1243-1255.

(34) Carless, H. A. J.; Atkins, R.; Fekarurhobo, G. K. Thermal and Photochemical Reactions of Unsaturated Bicyclic Endoperoxides. Tetrahedron Lett. 1985, 26, 803-806.

(35) (a) Adam, W.; Cueto, O.; De Lucchi, O.; Peters, K.; Peters, E.M.; von Schnering, H. G. Synthesis of the Endoperoxide Anti-7,8Dioxatricyclo[4.2.2.02,5]Deca-3,9-Diene via Singlet Oxygenation of the Bicyclic Valence Tautomer of Cyclooctatetraene and Its Transformations. J. Am. Chem. Soc. 1981, 103, 5822-5828. (b) Adam, W.; Adamsky, F.; Klärner, F.-G.; Peters, E.-M.; Peters, K.; Rebollo, H.; Rüngeler, W.; von Schnering, H. G. Stereochemistry and product distribution in the singlet oxygen cycloaddition with 7,7-disubstituted 1,3,5-cycloheptatrienes Chem. Ber. 1983, 116, 1848-1859.

(36) Ashton, P. R.; Ballardini, R.; Balzani, V.; Bělohradský, M.; Gandolfi, M. T.; Philp, D.; Prodi, L.; Raymo, F. M.; Reddington, M. V.; Spencer, N.; Stoddart, J. F.; Venturi, M.; Williams, D. J. SelfAssembly, Spectroscopic, and Electrochemical Properties of [n]Rotaxanes. J. Am. Chem. Soc. 1996, 118, 4931-4951.

(37) Saito, S.; Nakazono, K.; Takahashi, E. Template Synthesis of [2]Rotaxanes with Large Ring Components and Tris(Biphenyl)Methyl Group as the Blocking Group. The Relationship between the Ring Size and the Stability of the Rotaxanes. J. Org. Chem. 2006, 71, 7477-7480.

(38) Chodkiewicz, W.; Cadiot, P. New Synthesis of Symmetrical and asymmetrical conjugated polyacetylenes. Hebd. Seances Acad. Sci. 1955, 241, 1055-1057.

(39) Berná, J.; Goldup, S. M.; Lee, A. L.; Leigh, D. A.; Symes, M. D.; Teobaldi, G.; Zerbetto, F. Cadiot-Chodkiewicz Active Template Synthesis of Rotaxanes and Switchable Molecular Shuttles with Weak Intercomponent Interactions. Angew. Chem. Int. Ed. 2008, 47, 43924396.

\section{Table of contents graphic:}

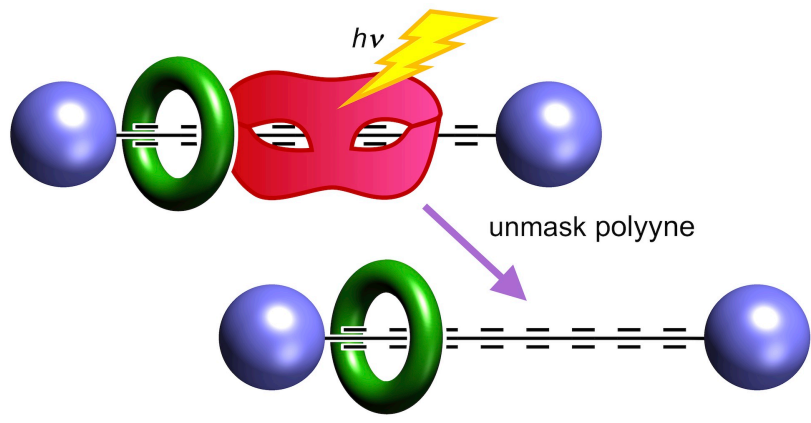

